\title{
Role of carotid intima-media thickness in the detección of subclinical atherosclerosis
}

Keywords: carotid intima-media thickness, subclinical atherosclerosis, risk marker

\section{Editorial}

Atherosclerosis is a systemic disease process that affects the arterial tree of the human body when it is exposed to elevated risk factor levels. ${ }^{1-3}$ Carotid intima media thickness (IMT) is a measure of early atherosclerosis and vascular remodelling that can be rapidly and non-invasively assessed with high-resolution ultrasound. Indeed, carotid IMT is widely utilized because it can be measured relatively simply, non-expensibly, and it is commonly utilized to investigate atherosclerosis. ${ }^{4-6}$ Increased carotid IMT is considered to represent a manifestation of subclinical atherosclerosis and it has been included in the European hypertension guidelines, ${ }^{7}$ and in the European prevention guidelines. ${ }^{8}$ The ultrasound technique measurement of carotid IMT is stated in the ACC/AHA 2010 guidelines as a tool for cardiovascular risk assessment in appropriately selected patients. Hence, assessment of carotid IMT has emerged as a simple and noninvasive technique for measuring atherosclerotic burden. ${ }^{9}$

In addition, in order to study the efficacy of pharmacological interventions in clinical trials, drug-induced regression or slow progression in carotid IMT in the follow-up period are being used as an alternative, or surrogate clinical end point for cardiovascular morbidity and mortality. ${ }^{1}$ Serum biomarkers have been widely utilized to assess the risk of developing atherosclerosis. Despite their benefits and their usefulness in this context, carotid IMT has the additional theoretical advantage of directly visualizing the final consequence of the disease itself, namely atherosclerosis in the vessel wall. The current widespread application of the ultrasound values of carotid IMT measurements has been based on the validity, standardization, and reproducibility of the technique, and the evidence that an increased carotid IMT can be regarded as a marker of atherosclerosis and of increased cardiovascular risk. ${ }^{10-16}$ This harmless ultrasound procedure has several advantages due to the lack of invasiveness and its usefulness of repeatability which makes carotid IMT measurement an attractive biomarker, potentially useful as a therapeutic target in those at increased cardiovascular risk. ${ }^{17}$

Despite major improvements performed in the therapeutic management of acute coronary syndromes decreasing its morbidity and mortality, it still remains as the number one cause of death in the world. ${ }^{18-22}$ This highlights the necessity to close the gaps that are left between risk assessment with traditional risk factors and the real clinical event. Evidence based medicine relies on clinical data from randomized controlled trials to guide therapeutic clinical decisions. Carotid IMT can be considered as a biomarker halfway between risk factors and organ damage that can help prevent clinical events. This approach avoids the substantial costs and lengthy follow-up required of traditional clinical trials that are focused on hard, but uncommon, clinical end points such as myocardial infarction, stroke, or death. ${ }^{11-13}$

\author{
Volume 4 Issue I - 2015 \\ Osmar Antonio Centurión \\ Department of Health Sciences Investigation, Sanatorio \\ Metropolitano, Fernando de la Mora, Paraguay

\begin{abstract}
Correspondence: Osmar Antonio Centurión, Professor of Medicine, Asuncion National University, Department of Health Sciences $\square$ s Investigation, Sanatorio Metropolitano, Teniente Ettiene $215 \mathrm{c} /$ Ruta Mariscal Estigarribia, Fernando de la Mora, Paraguay, Email osmarcenturion@hotmail.com
\end{abstract} \\ Received: November 17, 2015 | Published: November 18, \\ 2015
}

Although, ultrasound measurement is a well-validated technique that has undergone substantial technical improvements in both the manner of imaging and the IMT quantification, it is still a limited imaging modality for assessing carotid atherosclerosis. Newer noninvasive techniques such as magnetic resonance imaging have attractive properties that may improve the assessment of atheroma burden in this vascular territory. ${ }^{23}$ Carotid magnetic resonance imaging has already begun to be used for evaluating the artery wall changes associated with pharmacological treatment. ${ }^{24-28}$ The proper utilization of carotid resonance may lead to more accurate quantification of atherosclerotic burden and improve the correlation of IMT changes with clinical events. Anyway, regardless of the technique utilized to perform the measurements, carotid IMT measurements have increasingly been used in observational and interventional clinical studies. Carotid IMT has been applied as an outcome variable in studies on the determinants of atherosclerosis, and it has been employed as a biomarker in order to predict coronary artery disease and stroke. Change in carotid IMT over time as an indicator for atherosclerosis progression, has predominantly served in interventional studies as a primary outcome variable aimed at assessing the effects of risk factor interventions.

\section{Acknowledgments \\ None.}

\section{Conflicts of interest}

Author declares there are no conflicts of interest.

\section{Funding}

None.

\section{References}

1. Espeland MA, O’Leary DH, Terry JG, et al. Carotid intimal-media thickness as a surrogate for cardiovascular disease events in trials of HMG-CoA reductase inhibitors. Curr Control Trials Cardiovasc Med. 2005;6(1):3. 
2. Polak JF, O’Leary DH, Kronmal RA, et al. Sonographic evaluation of carotid artery atherosclerosis in the elderly: relationship of disease severity to stroke and transient ischemic attack. Radiology. 1993;188(2):363-370

3. Salonen R, Salonen JT. Determinants of carotid intima-media thickness: a population-based ultrasonography study in eastern Finnish men. $J$ Intern Med. 1991;229(3):225-231.

4. Bots ML, Hoes AW, Koudstaal PJ, et al. Common carotid intima-media thickness and risk of stroke and myocardial infarction: the Rotterdam study. Circulation. 1997;96(5):1432-1437.

5. Howard G, Burke GL, Evans GW, et al. Relations of intimal-medial thickness among sites within the carotid artery as evaluated by B-mode ultrasound. Stroke. 1994;25(8):1581-1587.

6. Lorenz MW, Markus HS, Bots ML, et al. Prediction of clinical cardiovascular events with carotid intima-media thickness: a systematic review and meta-analysis. Circulation. 2007;115(4):459-467.

7. Mancia G, De Backer G, Dominiczak A, et al. 2007 Guidelines for the Management of Arterial Hypertension: The Task Force for the Management of Arterial Hypertension of the European Society of Hypertension (ESH) and of the European Society of Cardiology (ESC). J Hypertens. 2007;25(6):1105-1187.

8. Graham I, Atar D, Borch-Johnsen K, et al. European Association for Cardiovascular Prevention and Rehabilitation (EACPR). European guidelines on cardiovascular disease prevention in clinical practice: executive summary. Eur J Cardiovasc Prev Rehabil. 2007;2(14 Suppl):E1-E40

9. McCullogh PA, Lepor NE. Lipids, biomarkers, and noninvasive imaging of atherosclerotic disease activity in clinical trials. Rev Cardiovasc Med . 2008;9(2):142-149.

10. Mancini GB. Carotid intima-media thickness as a measure of vascular target organ damage. Curr Hypertens Rep. 2000;2(1):71-77.

11. Bots ML, Grobbee DE. Intima media thickness as a surrogate marker for generalised atherosclerosis. Cardiovasc Drugs Ther. 2002;16(4):341-351.

12. de Groot E, Hovingh GK, Wiegman A, et al. Measurement of arterial wall thickness as a surrogate marker for atherosclerosis. Circulation . 2004;109(Suppl 1): III33-III38.

13. Amarenco P, Labreuche J, Lavallee P, Statins in stroke prevention and carotid atherosclerosis: systematic review and up-to-date meta-analysis. Stroke . 2004;35(12):2902-2909.

14. Poredos P. Intima-media thickness: indicator of cardiovascular risk and measure of the extent of atherosclerosis. Vasc Med. 2004;9(1):46-54.

15. Barth JD. Carotid intima media thickness and beyond. Curr Drug Targets Cardiovasc Haematol Disord . 2004;4(2):129-145.
16. Spence JD, Hegele RA. Non-invasive assessment of atherosclerosis risk. Curr Drug Targets Cardiovasc Haematol Disord. 2004;4(2):125- 128.

17. Vasan RS. Biomarkers of cardiovascular disease: molecular basis and practical considerations. Circulation. 2006;113(19):2335-2362.

18. Libby P. Mechanisms of the acute coronary syndromes and their implications for therapy. N Engl J Med. 2013;368(21):2004-2013.

19. Siontis GC, Stefanini GG, Mavridis D, et al. Percutaneous coronary interventional strategies for treatment of in-stent restenosis: a network meta-analysis. Lancet . 2015;386(9994):655-664.

20. Centurión OA. Actual role of platelet glycoprotein IIb/IIIa receptor inhibitors as adjuntive pharmacological therapy to primary angioplasty in acute myocardial infarction: In the light of recent randomized trials and observational studies with bivalirudin. Open Cardiovasc Med J. 2010;4:135-145.

21. Centurión OA. Bivalirudin in contemporary PCI for non-ST-segment acute coronary syndromes: ¿What is the current role of platelet glycoprotein IIb/IIIa receptor inhibitor agents? Crit Pathways in Cardiol. 2011;10(2):87-92.

22. Centurión OA. Heparin versus Bivalirudin in contemporary percutaneous coronary intervention: A welcome back to an old friend unfractionated heparin. Crit Pathw Cardiol. 2015;14(2):62-66.

23. Duivenvoorden R, de Groot E, Stroes ES, et al. Surrogate markers in clinical trials: Challenges and opportunities. Atherosclerosis. 2009;206(1):8-16

24. Zhao XQ, Phan BA, Chu B, et al. Testing the hypothesis of atherosclerotic plaque lipid depletion during lipid therapy by magnetic resonance imaging: study design of Carotid Plaque Composition Study. Am Heart J. 2007;154(2):239-246.

25. Underhill HR, Yuan C, Zhao XQ, et al. Effect of rosuvastatin therapy on carotid plaque morphology and composition in moderately hypercholesterolemic patients: a high-resolution magnetic resonance imaging trial. Am Heart J . 2008;155(3):584.e1-584.e8

26. Lee JM, Wiesmann F, Shirodaria C, et al. Early changes in arterial structure and function following statin initiation: quantification by magnetic resonance imaging. Atherosclerosis. 2008;197(2):951-958.

27. Airan-Javia SL, Wolf RL, Wolfe ML, et al. Atheroprotective lipoprotein effects of a niacin-simvastatin combination compared to low- and highdose simvastatin monotherapy. Am Heart J. 2009;157(4):687.e1-687. e8.

28. Miyauchi K, Takaya N, Hirose T, et al. Rationale and design of the carotid plaque in human for all evaluations with aggressive rosuvastatin therapy (CHALLENGER trial): evaluation by magnetic resonance imaging. Circ J. 2009;73(1):111-115. 